\title{
DNA Damage Response and Cell Cycle Regulation in Pluripotent Stem Cells
}

\author{
Andy Chun Hang Chen ${ }^{1,2}$, Qian Peng ${ }^{2}$, Sze Wan Fong ${ }^{1}$, Kai Chuen Lee ${ }^{1}$, William Shu Biu Yeung 1,2,* \\ and Yin Lau Lee ${ }^{1,2, *(D)}$ \\ 1 Department of Obstetrics and Gynaecology, Li Ka Shing Faculty of Medicine, The University of Hong Kong, \\ 21 Sassoon Road, Hong Kong, China; andycch0@hku.hk (A.C.H.C.); szewan11@hku.hk (S.W.F.); \\ bolkcad@gmail.com (K.C.L.) \\ 2 Shenzhen Key Laboratory of Fertility Regulation, Reproductive Medicine Center, The University of Hong \\ Kong Shenzhen Hospital, Shenzhen 518009, China; qianpeng_77@hotmail.com \\ * Correspondence: wsbyeung@hku.hk (W.S.B.Y.); cherielee@hku.hk (Y.L.L.)
}

Citation: Chen, A.C.H.; Peng, Q.; Fong, S.W.; Lee, K.C.; Yeung, W.S.B.; Lee, Y.L. DNA Damage Response and Cell Cycle Regulation in Pluripotent Stem Cells. Genes 2021, 12, 1548. https://doi.org/10.3390/genes12101548

Academic Editor: Jean Molinier

Received: 6 September 2021

Accepted: 28 September 2021

Published: 29 September 2021

Publisher's Note: MDPI stays neutral with regard to jurisdictional claims in published maps and institutional affiliations.

Copyright: (c) 2021 by the authors. Licensee MDPI, Basel, Switzerland. This article is an open access article distributed under the terms and conditions of the Creative Commons Attribution (CC BY) license (https:/ / creativecommons.org/licenses/by/ $4.0 /)$.

\begin{abstract}
Pluripotent stem cells (PSCs) hold great promise in cell-based therapy because of their pluripotent property and the ability to proliferate indefinitely. Embryonic stem cells (ESCs) derived from inner cell mass (ICM) possess unique cell cycle control with shortened G1 phase. In addition, ESCs have high expression of homologous recombination (HR)-related proteins, which repair doublestrand breaks (DSBs) through HR or the non-homologous end joining (NHEJ) pathway. On the other hand, the generation of induced pluripotent stem cells (iPSCs) by forced expression of transcription factors (Oct4, Sox2, Klf4, c-Myc) is accompanied by oxidative stress and DNA damage. The DNA repair mechanism of DSBs is therefore critical in determining the genomic stability and efficiency of iPSCs generation. Maintaining genomic stability in PSCs plays a pivotal role in the proliferation and pluripotency of PSCs. In terms of therapeutic application, genomic stability is the key to reducing the risks of cancer development due to abnormal cell replication. Over the years, we and other groups have identified important regulators of DNA damage response in PSCs, including FOXM1, SIRT1 and PUMA. They function through transcription regulation of downstream targets (P53, CDK1) that are involved in cell cycle regulations. Here, we review the fundamental links between the PSC-specific HR process and DNA damage response, with a focus on the roles of FOXM1 and SIRT1 on maintaining genomic integrity.
\end{abstract}

Keywords: DNA damage; cell cycle regulation; pluripotent stem cells (PSCs); FOXM1; SIRT1

\section{Introduction}

Embryonic stem cells (ESCs) of mice [1] or humans [2] are derived from the ICM of blastocysts. They hold great promise in cell-based therapy because of their pluripotent nature and the ability to proliferate indefinitely. Since the advent of ESCs decades ago, a massive number of protocols were developed to drive them into different germ layers (endoderm, mesoderm and ectoderm) through manipulation of cell signaling pathways. For instance, we [3] and other research groups [4,5] have reported the differentiation of human ESCs (hESCs) into pancreatic lineages. Extensive work was also done to drive hESCs into trophoblast [6,7] and germ cell [8] lineages. Therefore, ESC is an excellent in-vitro model for understanding early developmental events and their interactions with external stimuli [3,9]. Notwithstanding the potential applications of ESCs in regenerative medicine, tissue rejection in recipients could be a main concern. In 2006, Yamanaka and his team reported the generation of induced pluripotent stem cells (iPSCs) from mouse embryonic and adult fibroblasts through induction of transcription factors (Oct4, Sox2, Klf4 and c-Myc) [10]. A year later, they also reported the generation of iPSCs from human fibroblasts [11]. As patient-specific iPSCs can be derived, these ground-breaking iPSCs solved the major hurdle of tissue rejection in cell-based therapy. 
Understanding the biological characteristics of pluripotent stem cells (PSCs) is imperative for exploring their potential applications. In fact, both ESCs and iPSCs can proliferate rapidly. The doubling time of PSCs ranges from $8-10 \mathrm{~h}$, which is much faster than that in somatic cells (around $20 \mathrm{~h}$ ) [11-13]. Interestingly, the fast cell division is reminiscent of early embryonic cells, with doubling time of $5-10 \mathrm{~h}$ before implantation [14]. Studies suggested that the rapid proliferation of PSCs was due to their unique cell cycle regulations. For instance, PSCs have a shortened G1 phase as a result of low expression of G1 phase-specific cyclin D and cyclin-dependent kinases (CDK) 4 and 6 . The interplay between cyclins, CDK and cyclin-dependent kinase inhibitors (CDKN) is important for tight regulation of cell cycle progression $[15,16]$. Cell cycle regulation is highly related to pluripotency in PSCs, as the master pluripotent marker Oct4 controls the progression of cell cycle [17]. In addition, the cell cycle regulators have important functions in DNA damage response (DDR) of PSCs [18]. Replication stress and DNA damage were induced by the shortened G1 phase in mouse ESCs (mESCs) [19]. More importantly, the expression levels of DNA damage marker $\gamma \mathrm{H} 2 \mathrm{AX}$ increased during the reprogramming process into iPSCs [20]. Thus, the DDR system in PSCs is essential for minimizing the accumulation of DNA mutations and maintaining genomic integrity in the highly proliferating cells [21]. In this review, we discuss the relationship between cell cycle regulation and DDR in PSCs and the recent discoveries of important regulators, including FOXM1, SIRT1 and PUMA, in regulating DDR in PSCs.

\section{Cell Cycle Regulation in Pluripotent Stem Cells (PSCs)}

The mitotic cell division is the most fundamental process for all cell types. It is tightly regulated by the activation and deactivation of cyclin-dependent kinases (CDK) and the oscillatory expression of cyclins at different stages of the cell cycle. The canonical cell cycle in somatic cells consists of a DNA synthesis phase ( $\mathrm{S}$ phase) and a cell division phase (M phase). G1 (between M and S phase) and G2 (between S and M phase) are two gap phases in between $S$ and $M$ phases. In each cell cycle, cyclin D and its CDK partner CDK4/6 are highly expressed in the G1 phase. Cyclin $\mathrm{E}$ and its partner CDK2 are predominantly active between the late $\mathrm{G} 1$ and $\mathrm{S}$ phase, while cyclin A/E with its partner CDK2 are mainly active between the S and G2 phase. Lastly, cyclin B and its partner CDK1 mainly regulate the G2 and M phase [22]. The oscillatory appearance of cyclins and CDKs are important for ensuring the correct sequences of DNA synthesis prior to cell division, thus controlling genomic integrity. Early studies in mouse blastomeres showed that their cell cycle closely resembled that of the canonical model. Later, it was found that the mouse embryonic cells have rapid cell divisions with doubling time of 5-10 h, owing to the shortened and truncated G1 and G2 phases [23].

\subsection{Cell Cycle Regulation in $m E S C S$}

The fast cell cycle of mESCs is accompanied by a shortened G1 phase. Interestingly, the oscillatory expression and activities of the cyclin-CDK complexes in mESCs are quite different from that in somatic cells $[24,25]$. First of all, since the G1 phase is significantly shortened, the cyclin D (i.e., cyclin D1 and D3) is expressed at low levels. Throughout the cell cycle, Cdk6 becomes the predominant partner at the G1 phase with an oscillatory expression pattern. On the other hand, cyclin A/E and their partner Cdk2 are expressed at high levels in mESCs. The high expression is cell cycle independent and without oscillation. Lastly, the expression patterns of the mitotic cyclin B and its partner Cdk1 are similar to those in somatic cells; they have oscillatory expression throughout the cell cycle and are only expressed highly in the G2/M phase [24,25].

In addition to the tight regulations of the expression of the cyclin-CDK complexes, another key cell cycle regulator is the retinoblastoma protein (RB). In somatic cells, RB is unphosphorylated and active in the G1 phase. The active RB couples with E2F and binds to the promoters of target genes expressed in the G1/S phase, such as components of the cyclin A/E-Cdk2 complex. The binding of E2F at the promoters leads to histone 
deacetylation and repression of gene expression. When the cells are ready to enter the $S$ phase, the RB is phosphorylated and does not repress the cyclin A/E-Cdk2 complex when entering the S phase [26]. The hypo-phosphorylation of RB at the G1 phase and the hyperphosphorylation of $\mathrm{RB}$ at the $\mathrm{S}$ phase add another level of cell cycle checkpoint to ensure proper cell cycle progression. Interestingly, the inactive hyper-phosphorylated RB is found in mESCs throughout different phases of the cell cycle. The reason is due to the high expression and activities of the cyclin A/E-Cdk2 complex, which lead to phosphorylation of RB [27].

\subsection{Cell Cycle Regulation in $\mathrm{hESCS}$}

Human ESCs, though derived from the ICM of human blastocysts, are considered as being at a primed state similar to that of mouse epiblast stem cells (mEpiSCs). On the other hand, mESCs are generally defined as being in a naïve state [28]. It is therefore reasonable that there are major differences in cell cycle regulation between mESCs and hESCs. Indeed, hESCs have a longer and more functional G1 phase compared with mESCs. Therefore, the cyclin Ds (i.e., cyclin D1, D2 and D3) have intermediate expression in the G1 phase in hESCs, though their expression is still lower than that in somatic cells. Unlike the mESCs, the expression of cyclin D partner CDK4 is higher than CDK6 in hESCs $[13,15]$. Another major difference between mESCs and hESCs is that the expression pattern of the cyclin A/E-CDK2 complex is cell cycle dependent in hESCs, but it is constant in mESCs. Moreover, the functional RB checkpoint at the G1 phase guarding the correct entry into $S$ phase occurs in hESCs but not in mESCs [15]. On the other hand, there is similarity between mESCs and hESCs; the oscillatory patterns with high expression of the mitotic related cyclin B and its partner CDK1 are observed at the G2/M phase. The expression patterns of cyclin, CDKs and RB in mESCs and hESCs are summarized in Table 1.

Table 1. Expression levels of cyclins, cyclin-dependent kinases (CDKs) and phosphorylation status of retinoblastoma protein (RB) in mESCs and hESCs during cell cycle progression.

\begin{tabular}{|c|c|c|}
\hline & mESCs & hESCs \\
\hline \multicolumn{3}{|c|}{ Cyclin expression levels } \\
\hline Cyclin A/E & High, non-oscillatory & High, oscillatory \\
\hline Cyclin B & High, oscillatory & High, oscillatory \\
\hline Cyclin D & Low, oscillatory & Intermediate, oscillatory \\
\hline \multicolumn{3}{|c|}{ CDKs expression levels } \\
\hline CDK1 & High, oscillatory & High, oscillatory \\
\hline CDK2 & High, non-oscillatory & High, oscillatory \\
\hline CDK4 & Low, oscillatory & Medium, oscillatory \\
\hline CDK6 & Medium, oscillatory & Low, oscillatory \\
\hline \multicolumn{3}{|c|}{ RB phosphorylation } \\
\hline $\mathrm{RB}$ & Hyper-phosphorylated & Hypo-/Hyper-phosphorylated \\
\hline
\end{tabular}

\subsection{Cell Cycle Regulation and Pluripotency}

Octamer-binding transcription factor 3/4 (OCT4) or POU class 5 homeobox 1 (POU5F1) is the most critical transcription factor for maintaining the pluripotency in both mESCs and hESCs [1,2]. Knockout of OCT4 leads to loss of pluripotency [29-31]. In the past decade, research on OCT4 focused on its role in cell cycle regulation. For instance, OCT4 downregulates the expression of cyclin D1 for shortening the G1 phase in hESCs. The mediation is through transcriptional regulation of the mir-302 cluster by OCT4 and depletion of the miR-302 cluster that extends the G1 phase in hESCs [32], highlighting the importance of OCT4 in cell cycle regulation. In mESCs, on the other hand, Oct4 activates the expression of $E 2 f 3 a$, which positively regulates the transcription of cyclin A and Cdk1 for the fast proliferation of mESCs [33]. It should be noted that other pluripotent markers such as 
NANOG and SOX2 are also important in cell cycle regulation through interaction with other modulators [34,35]. Collectively, the current evidence shows that pluripotency and cell cycle regulation are highly connected in PSCs.

\section{DNA Damage Response and Cell Cycle Regulation}

\subsection{Cell Cycle Checkpoints and DNA Damage Response}

Apart from the cyclin-CDK complexes and the RB protein, the cyclin-dependent kinase inhibitors $(\mathrm{CDKN})$ are also important for cell cycle progression. Generally, there are two major groups of $\mathrm{CDKNs}$, including the $\mathrm{CDK}$ interacting protein/kinase inhibitory protein (CIP/KIP) and the inhibitors of the CDK4/alternate reading frame (INK4/ARF) family. The CIP/KIP family consists of subunits P21(CIP1), P27(KIP1) and P57(KIP2), while the INK4/ARF family consists of P16(INK4A), P15(INK4B), P18(INK4C) and P19(INK4D/ARF) [25]. CDKNs inhibit the activities of cyclins and CDKs. As the levels of CDKNs in PSCs are low [27], the expression of cyclin-CDK complexes can be maintained at high levels for fast cell cycle progression. A study even suggested that some CDKNs might not be functional in mESCs, as the cyclin D3-Cdk6 expression was not affected by overexpression of its upstream CDKN regulator $p 16$ [36].

The CDKNs not only act as cell cycle checkpoints but also are heavily linked to DNA damage response. For instance, P53 is a tumor suppressor gene and responsible for regulating genome stability. In response to DNA double-strand breaks (DSB), P53 can directly activate the ataxia-telangiectasia mutated (ATM) kinase through phosphorylation. The ATM kinase is then recruited to the site of DNA damage for repairing, either through homologous recombination (HR) or non-homologous end joining (NHEJ) [37]. More importantly, P53 also activates P21, which in turn inhibits cyclin A/E-CDK2 activity, leading to blockage of G1/S phase entry [38]. In PSCs, P53 is activated during DNA damage. The induction of P53 in turn suppresses pluripotent marker (OCT4 and NANOG) expression in mESCs and hESCs, leading to their differentiation [39].

\subsection{DNA Repairing Mechanisms in PSCs}

A precise DNA repair system is imperative in PSCs. The system allows the cells to cope with DNA lesions and maintain their genomic integrity during rapid cell cycle progression. In PSCs, the system is tightly controlled by DNA damage response (DDR) signaling. Generally, PSCs respond to DNA damage or lesions through DDR, leading to cell cycle arrest and increased expression of DNA repair genes [40]. Cell cycle arrest at either the G1/S or the G2/M-phase allows incorporation of different DNA repair mechanisms, including mismatch repair (MMR), base excision repair (BER), nucleotide excision repair (NER), HR and NHEJ.

The PSCs have a short G1 phase that can help to minimize the induction of differentiationrelated signaling. Therefore, some of the DNA repair mechanisms occurring at the G1 phase checkpoint in somatic cells are bypassed in PSCs. The prolonged S phase makes the PSCs utilize HR preferentially over other DNA repair pathways during DDR [41]. The genes involved in HR, including RAD51 and RAD52, are highly expressed in the $\mathrm{S}$ phase of DNA repair. In addition to these genes, the MRE11- RAD50-NBS1 (MRN) complex is also involved in DNA repair through HR and NHEJ. They serve as a DNA damage sensor and generate single stranded DNA regions that activate the checkpoint responses. Following the activation, the checkpoint transmits and amplifies the signal to downstream targets such as the cyclin-CDK complex and other DNA repair-related genes [42,43].

\section{Critical Regulators of DNA Damage Response in PSCs}

\subsection{FOXM1}

Forkhead box (FOX) is a superfamily of transcription factors widely expressed in many tissues. Members of the superfamily share an evolutionary conserved winged-helix DNA-binding domain. To date, more than 50 FOX proteins are identified and are subgrouped from FOXA to FOXS based on their sequence homologies. They are involved 
in many cellular processes, including cell cycle progression, angiogenesis, apoptosis and response to DNA damage [44].

Forkhead box M1 (FOXM1) is a member of the FOX superfamily consisting of a Nterminal repressor domain and a C-terminal transactivation domain. Foxm 1 is crucial for embryogenesis in mice. Foxm1 is highly expressed in the epithelial and mesenchymal cells during early embryo development. The patterned expression is important for further development into organs such as liver, lung, intestine and urinary tract [45]. The expression of Foxm1 in differentiated adult tissue is low, and increases in FOXM1 expression are correlated with the initiation of cancer formation and tumor initiation [46,47]. We have identified FOXM1 to be highly expressed in hESCs [48]. In the following sections, we discuss the roles of FOXM1 in DDR and cell cycle regulation in PSCs.

\subsubsection{FOXM1 and DNA Damage Response in PSCs}

FOXM1 is one of the master regulators in initiating DDR. Foxm1-deficient mouse embryonic fibroblasts (MEFs) have more DNA breaks than wildtype MEFs, as shown by increased level of $\gamma \mathrm{H} 2 \mathrm{AX}$. FOXM1 transcriptionally activates X-ray cross-complementing group 1 (Xrcc1) and breast cancer-associated gene 2 (Brca2), which are involved in base excision repair and HR repair, respectively, for DSBs [49]. Concerning the HR repair pathway, FOXM1 upregulates the expression of NBS1 in human breast cancer cells [50]. NBS1 is a subunit in the MRN complex responsible for DSB repair through HR and NHEJ. FOXM1 also enhances the recruitment of the ATM kinase at the sites of DNA damage [50]. The ATM kinase then promotes the phosphorylation of a number of proteins, including P53, H2AX, BRCA1 and NBS1 that are involved in cell cycle arrest and DNA repair [51]. Conversely, depletion of FOXM1 and NBS1 through an si-RNA approach led to the loss of HR repair ability in breast cancer cells, resulting in accumulation of $\gamma \mathrm{H} 2 \mathrm{AX}$ foci and induction of cellular senescence [50].

FOXM1 also regulates HR repair through transcriptional activation of S-phase kinaseassociated protein 2 (SKP2) and cyclin-dependent kinases regulatory subunit 1 (CKS1). In human cancer cells, FOXM1 binds to the promoters of SKP2 and CKS1 and activates them [52]. Both SKP2 and CKS1 are important subunits of the Skp1-Cullin 1-F-box (SCF) ubiquitin ligase complex that interacts with NBS1 and triggers its ubiquitination upon DNA DSB. This process facilitates the recruitment of ATM ligase at the sites of DNA damage and hence induces DNA repair through HR and NHEJ [53]. As most of the studies were performed in human cancer cells, the exact roles of FOXM1 in DDR in ESCs or during reprogramming to iPSCs are yet to be investigated. However, DNA damage is apparent during acquisition of pluripotency from somatic cells such as MEFs [20]. It is believed that FOXM1 should play similar roles in regulating DDR in ESCs, as described above. The known interactions of FOXM1 with DDR-related genes are summarized in Figure 1.

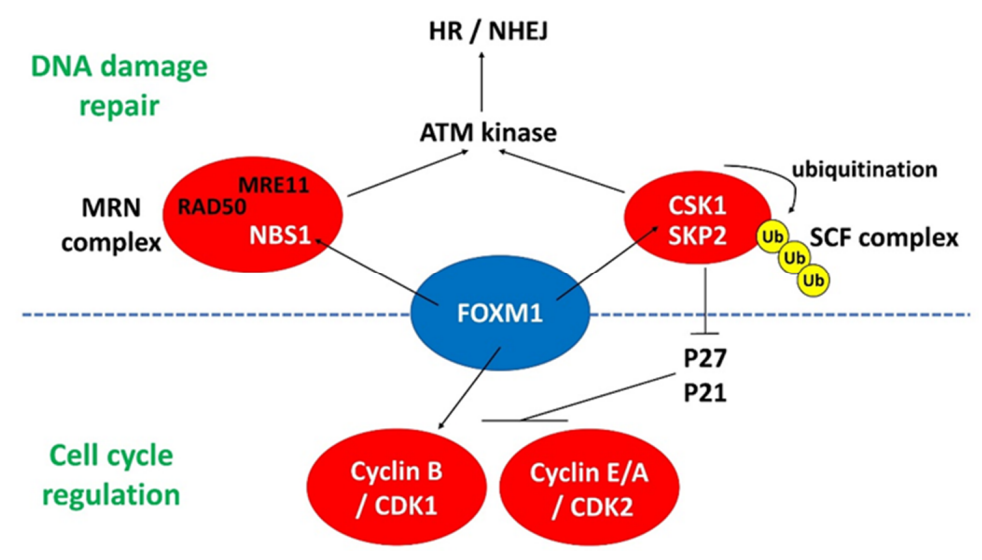

Figure 1. The interactions of FOXM1 with different regulators involved in DNA damage repair and cell cycle progression. MRN complex: MRE11/RAD50/NBS1; HR: homologous recombination; NHEJ: non-homologous end joining; Ub: ubiquitination. 


\subsubsection{FOXM1 and CDKs in PSCs}

DDR and cell cycle regulation are highly interconnected; therefore, FOXM1 also interacts with a couple of cyclin-dependent kinases (CDK) (Figure 1). FOXM1 activates SKP2 and CKS1 in human cancer cells. The elevated SKP2 and CKS1 downregulates the expression of $P 27$ and $P 21$ that is mainly responsible for inhibiting the activity of cyclin E/A-CDK2 and cyclin B-CDK1 complexes. As a result, the activities of the two cyclin complexes are dramatically reduced in FOXM1-depleted human cancer cells and MEFs [53]. There is not much research focusing on the roles of FOXM1 in cell cycle regulation of PSCs. FOXM1 binds to gene promoters that regulate cell cycle progression, including CDK12, $P 21, C D C 20$, and CDC5 in hESC-derived retinal pigment epithelium (hESC-RPE) cells [54]. Since both CDKs and CDKNs are transcriptionally regulated by FOXM1, their combined effects on the enhanced proliferation of hESC-RPE cells remain to be determined. We have reported the roles of FOXM1 in hESCs [48]. FOXM1 is highly expressed in undifferentiated hESCs, with a higher expression level in the G2/M phase than the G1 and S phase. Through chromatin immunoprecipitation sequencing (ChIP-seq), we found for the first time that FOXM1 bound to the promoters of cyclin B1 (CCNB1) and CDK1 in the undifferentiated hESCs, and that depletion of FOXM1 led to impaired proliferation in hESCs. The study provides direct evidence that FOXM1 regulates cell cycle progression through transcription activation of the cyclin-CDK complex. The interactions of FOXM1 with various cell cycle regulators are shown in Figure 1.

\subsection{SIRT1}

Sirtuin 1 (SIRT1) belongs to the sirtuin family. The human sirtuin family consists of seven members (SIRT1 to SIRT7). They have highly conserved domain that acts as a nicotinamide adenosine dinucleotide (NAD)-dependent histone deacetylase [55]. Among the sirtuin members, SIRT1 is the most widely studied molecule. It is detected in the nucleus and involved in many cellular events including transcriptional silencing, DNA damage repair, cell cycle regulation, insulin regulation and longevity [56-60]. As a histone deacetylase, SIRT1 is recruited to the chromatin and deacetylates histone 1 lysine 26 (H1K26), H3K9, H3K14 and H4K16 [61]. In addition, SIRT1 also deacetylates a number of transcription factors, including P53, FOXO, p300 histone acetyltransferase and E2F transcription factor 1 (E2F1) [62]. We and others have demonstrated that SIRT1 is highly expressed in both mESCs and hESCs $[56,57,63]$. In the following section, we review the importance of SIRT1 in regulating cell cycle progression and DDR.

\subsubsection{SIRT1 and P53}

P53 is important for cell cycle regulation and DDR. SIRT1 is an important regulator of P53 in PSCs and highly expressed in undifferentiated hESCs. It inactivates P53 expression through its protein deacetylase property. OCT4 regulates the activity of SIRT1. Downregulation of OCT4 reduces SIRT1 expression and upregulates P53 activity. Consistently, depletion of SIRT1 in hESCs led to stabilization of the P53 protein and hence its activity due to acetylation at the K120 and K164 sites [64]. It is noted that SIRT1 is important for cell survival in undifferentiated but not in differentiated cells. The depletion of SIRT1 upregulates P53 activity in the undifferentiated hESCs but not in other cell types, leading to programmed cell death related to decreased expression of DNA repair enzymes such as MSH2, MSH6 and APEX1 in hESCs [65].

SIRT1 is also the upstream regulator of p53 in miPSCs [57]. A similar relationship between SIRT1 and p53 is found during reprogramming of mouse MEFs into iPSCs. The expression of SIRT1 level is increased during reprogramming of mouse MEFs. The deacetylation of p53 by SIRT1 increases the expression of Nanog, which facilitates the reprogramming of MEF. On the other hand, inhibition of SIRT1 by miR-34a reduces the reprogramming efficiency [57]. 


\subsubsection{SIRT1 and DNA Damage Response Genes}

Given the importance of SIRT1 in efficient reprogramming of MEFs into miPSCs and increased DNA damage markers such as $\gamma \mathrm{H} 2 \mathrm{AX}$ during the iPSC reprogramming process [20], SIRT1 should have some roles in DDR during reprogramming. In fact, SIRT1 is responsible for deacetylation of NBS1 in the MRN complex, leading to phosphorylation of NBS1 for recruiting ATM kinase to the site of DNA damage [66]. Either NBS1 depletion or its hyperacetylation reduces DNA repair and cell survival [66]. In addition, SIRT1 also deacetylates another important DNA repair partner WRN protein and promotes its translocation for DNA repair $[67,68]$.

Recently, we found that miR-135a regulated SIRT1 expression during miPSCs reprogramming. By immunoprecipitation, SIRT1 was found to interact with Wrn and Ku70 to form a protein complex in the initial phase of reprogramming [56]. The Wrn protein interacts with the Ku70/80 heterodimer [69], indicating that Wrn has a direct role in NHEJ. Thus, our results suggested direct involvement of SIRT1 in DSB repair during reprogramming. The increase in DNA repair in turn improved the reprogramming efficiency. Apart from Ku70 and Wrn, the MRN complex is important in HR-mediated DSB repair [70]. We found that the MRN complex components Mre11 and Rad50 were included within the complex of SIRT1 during reprogramming. Added together, the findings suggested that SIRT1 is an important regulator interacting with different complexes for DNA repair in response to DNA damage. The interactions of SIRT1 with various cell cycle and DNA damage response regulators are illustrated in Figure 2.

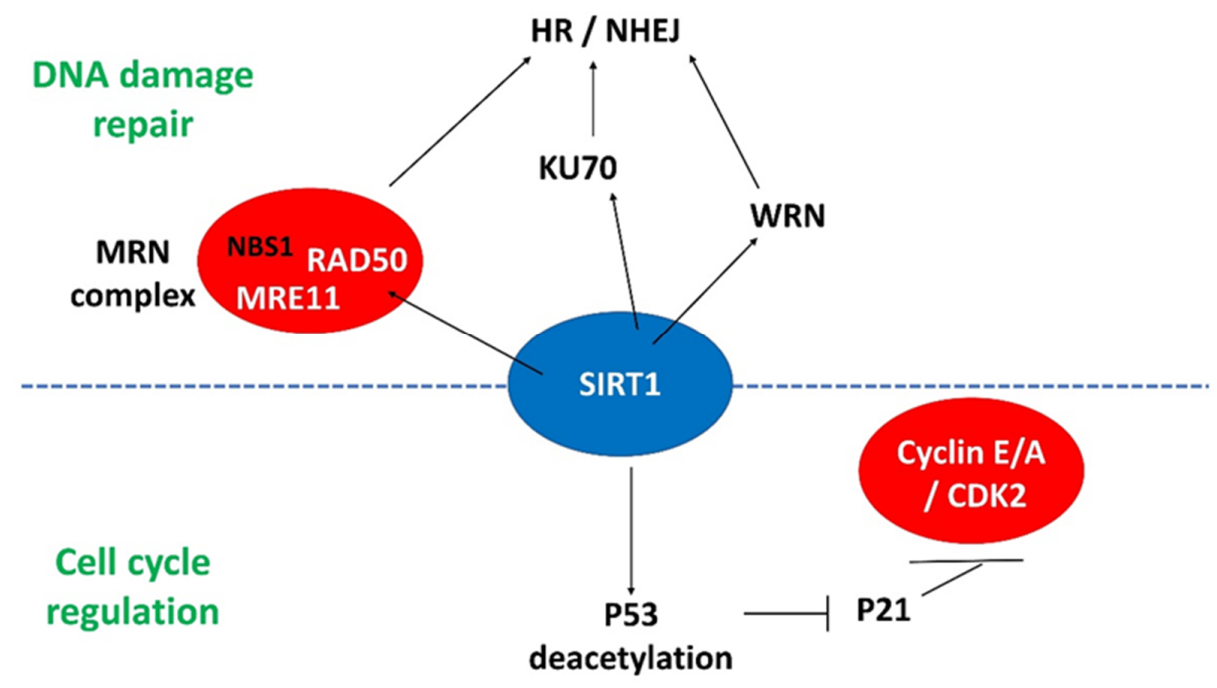

Figure 2. The interactions of SIRT1 with different regulators involved in DNA damage repair and cell cycle progression. MRN complex: MRE11/RAD50/NBS1; HR: homologous recombination; NHEJ: non-homologous end joining.

\subsection{Interplay between FOMX1 and SIRT1}

Though FOXM1 and SIRT1 regulate different downstream modulators during cell cycle progression and DDR, these two modulators might be connected. In human breast cancer tissues, FOXM1 protein expression level is highly correlated with that of SIRT1 [71]. It was reported that SIRT1 deacetylated and reduced expression of FOXO3. As FOXO3 negatively regulates FOXM1, the reduced FOXO3 expression level in turn increased FOXM1 level, which suggested SIRT1 might indirectly induce FOXM1 expression [72]. However, opposite findings that SIRT1 reduced FOXM1 expression were also reported. In breast cancer cells, SIRT1 was found to deacetylase mitogen-activated protein kinase 1 (MAP2K1), leading to inactivation of the MEK/ERK cell signaling pathway and reduction in FOXM1 protein. Consistently, the phenomenon was also observed in MEFs, indicating that the 
relationship was not restricted to cancer cells [73]. Another study even showed that SIRT1 directly bound to and deacetylated FOXM1 to suppress its expression [74].

FOXM1 was also reported to be the upstream regulator of SIRT1; FOXM1 regulated the chromatin structure remodeling and induced transcriptional activation of SIRT1 [75]. In cancer glioma cells, downregulation of FOXM1 by siRNA reduces SIRT1 expression. Critically, a FOXM1 binding site on the SIRT1 promoter has been identified [75]. The relationship between FOXM1 and SIRT1 in PSCs remains largely unknown. More mechanistic studies are required to investigate whether a feedback loop exists between the two genes and how their interplay affects DDR in PSCs.

\section{4. РUMA}

P53 upregulated modulator of apoptosis (PUMA) is another factor that recently emerged to regulate cell cycle progression and inhibit DDR in PSCs. As the name implies, PUMA is a direct target of P53. It has been implicated in causing cell apoptosis following irradiation in intestinal progenitor cells [76] and hematopoietic stem cells [77]. PUMA knockout in human iPSCs enhances DNA repair abilities of the cells, as shown by decreased $\gamma \mathrm{H} 2 \mathrm{AX}$-positive cells when compared with the wildtype cells after irradiation. Mechanistic analysis demonstrated that PUMA formed a protein complex with early mitotic inhibitor 1 (EMI1) and RAD51 in the cytoplasm of PSCs and promoted the ubiquitination and degradation of RAD51. The relationship was supported by an increase in RAD51 nuclear translocation post-irradiation in the PUMA ${ }^{-/-}$PSCs [78]. Since RAD51 is a DDR-related protein responsible for repairing through HR [79], the increased cell survival following irradiation in the PUMA-deficient cells could be the result of enhanced DNA repair. We have previously reported that P53 was a target of SIRT1 [57]. Coincidently, SIRT1 inhibition upregulates PUMA through modulating P53 activity [65]. It is therefore possible that SIRT1 could be the upstream regulator of PUMA in PSCs for mediating DDR.

\section{Concluding Remarks}

In this article, we reviewed the unique features of cell cycle regulation and DDR in PSCs. The observations showed that the regulatory mechanisms are tightly related to the maintenance of pluripotency. We also summarized research on how FOXM1, SIRT1 and PUMA regulated cell cycle and DDR in PSCs. Further research on the mechanisms in preserving genome integrity of PSCs could possibly provide new insights into PSCs application in cell-based therapy and a better understanding of the longevity of cells.

Author Contributions: Writing—original draft preparation, A.C.H.C. and Y.L.L.; writing-review and editing, Q.P., S.W.F., K.C.L., W.S.B.Y. and Y.L.L.; supervision, W.S.B.Y. and Y.L.L. All authors have read and agreed to the published version of the manuscript.

Funding: This research was funded by the General Research Fund (No. 775711) from the Research Grants Council, Hong Kong; Sanming Project of Medicine in Shenzhen, China (No. SZSM201612083), and the HKU-SZH Fund for Shenzhen Key Medical Discipline (No. SZXK2020089).

Institutional Review Board Statement: Not applicable.

Informed Consent Statement: Not applicable.

Data Availability Statement: Not applicable.

Conflicts of Interest: The authors declare no conflict of interest.

\section{References}

1. Evans, M.J.; Kaufman, M.H. Establishment in culture of pluripotential cells from mouse embryos. Nature 1981, 292, 154-156. [CrossRef]

2. Thomson, J.A.; Itskovitz-Eldor, J.; Shapiro, S.S.; Waknitz, M.A.; Swiergiel, J.J.; Marshall, V.S.; Jones, J.M. Embryonic Stem Cell Lines Derived from Human Blastocysts. Science 1998, 282, 1145-1147. [CrossRef] 
3. Chen, A.C.H.; Lee, Y.L.; Fong, S.W.; Wong, C.C.Y.; Ng, E.; Yeung, S.B.W. Hyperglycemia impedes definitive endoderm differentiation of human embryonic stem cells by modulating histone methylation patterns. Cell Tissue Res. 2017, 368, 563-578. [CrossRef]

4. $\quad$ Russ, A.H.; Parent, A.V.; Ringler, J.J.; Hennings, T.G.; Nair, G.G.; Shveygert, M.; Guo, T.; Puri, S.; Haataja, L.; Cirulli, V.; et al. Controlled induction of human pancreatic progenitors produces functional beta-like cells in vitro. EMBO J. 2015, 34, 1759-1772. [CrossRef]

5. Rezania, A.; Bruin, J.E.; Riedel, M.J.; Mojibian, M.; Asadi, A.; Xu, J.; Gauvin, R.; Narayan, K.; Karanu, F.; O’Neil, J.J.; et al. Maturation of human embryonic stem cell-derived pancreatic progenitors into functional islets capable of treating pre-existing diabetes in mice. Diabetes 2012, 61, 2016-2029. [CrossRef] [PubMed]

6. Amita, M.; Adachi, K.; Alexenko, A.P.; Sinha, S.; Schust, D.J.; Schulz, L.; Roberts, R.M.; Ezashi, T. Complete and unidirectional conversion of human embryonic stem cells to trophoblast by BMP4. Proc. Natl. Acad. Sci. USA 2013, 110, E1212-E1221. [CrossRef] [PubMed]

7. Lee, Y.L.; Fong, S.-W.; Chen, A.C.; Li, T.; Yue, C.; Lee, C.-L.; Ng, E.; Yeung, S.B.W.; Lee, K.-F. Establishment of a novel human embryonic stem cell-derived trophoblastic spheroid implantation model. Hum. Reprod. 2015, 30, 2614-2626. [CrossRef]

8. Irie, N.; Weinberger, L.; Tang, W.W.; Kobayashi, T.; Viukov, S.; Manor, Y.S.; Dietmann, S.; Hanna, J.H.; Surani, M.A. SOX17 Is a Critical Specifier of Human Primordial Germ Cell Fate. Cell 2015, 160, 253-268. [CrossRef] [PubMed]

9. Kubi, J.A.; Chen, A.C.; Fong, S.W.; Lai, K.P.; Wong, C.K.; Yeung, W.S.; Lee, K.F.; Lee, Y.L. Effects of 2,3,7,8-tetrachlorodibenzop-dioxin (TCDD) on the differentiation of embryonic stem cells towards pancreatic lineage and pancreatic beta cell function. Environ. Int. 2019, 130, 104885. [CrossRef]

10. Takahashi, K.; Yamanaka, S. Induction of Pluripotent Stem Cells from Mouse Embryonic and Adult Fibroblast Cultures by Defined Factors. Cell 2006, 126, 663-676. [CrossRef]

11. Takahashi, K.; Tanabe, K.; Ohnuki, M.; Narita, M.; Ichisaka, T.; Tomoda, K.; Yamanaka, S. Induction of Pluripotent Stem Cells from Adult Human Fibroblasts by Defined Factors. Cell 2007, 131, 861-872. [CrossRef] [PubMed]

12. White, J.; Dalton, S. Cell Cycle Control of Embryonic Stem Cells. Stem Cell Rev. Rep. 2005, 1, 131-138. [CrossRef]

13. Becker, K.A.; Ghule, P.N.; Therrien, J.A.; Lian, J.B.; Stein, J.L.; van Wijnen, A.J.; Stein, G.S. Self-renewal of human embryonic stem cells is supported by a shortened G1 cell cycle phase. J. Cell. Physiol. 2006, 209, 883-893. [CrossRef] [PubMed]

14. Wong, C.C.; Loewke, K.E.; Bossert, N.L.; Behr, B.; De Jonge, C.J.; Baer, T.M.; Reijo Pera, R.A. Non-invasive imaging of human embryos before embryonic genome activation predicts development to the blastocyst stage. Nat. Biotechnol. 2010, 28, 1115-1121. [CrossRef] [PubMed]

15. Neganova, I.; Zhang, X.; Atkinson, S.; Lako, M. Expression and functional analysis of G1 to S regulatory components reveals an important role for CDK2 in cell cycle regulation in human embryonic stem cells. Oncogene 2009, 28, 20-30. [CrossRef] [PubMed]

16. Lange, C.; Calegari, F. Cdks and cyclins link G1length and differentiation of embryonic, neural and hematopoietic stem cells. Cell Cycle 2010, 9, 1893-1900. [CrossRef] [PubMed]

17. Lee, J.; Go, Y.; Kang, I.; Han, Y.; Kim, J. Oct-4 controls cell-cycle progression of embryonic stem cells. Biochem. J. 2010, 426, 171-181. [CrossRef]

18. Hustedt, N.; Durocher, D. The control of DNA repair by the cell cycle. Nat. Cell Biol. 2017, 19, 1-9. [CrossRef]

19. Ahuja, A.K.; Jodkowska, K.; Teloni, F.; Bizard, A.H.; Zellweger, R.; Herrador, R.; Ortega, S.; Hickson, I.D.; Altmeyer, M.; Mendez, J.; et al. A short G1 phase imposes constitutive replication stress and fork remodelling in mouse embryonic stem cells. Nat. Commun. 2016, 7, 10660. [CrossRef]

20. Vallabhaneni, H.; Lynch, P.J.; Chen, G.; Park, K.; Liu, Y.; Goehe, R.; Mallon, B.S.; Boehm, M.; Hursh, D.A. High Basal Levels of $\gamma \mathrm{H} 2 \mathrm{AX}$ in Human Induced Pluripotent Stem Cells Are Linked to Replication-Associated DNA Damage and Repair. Stem. Cells 2018, 36, 1501-1513. [CrossRef]

21. Choi, E.-H.; Yoon, S.; Koh, Y.E.; Seo, Y.-J.; Kim, K.P. Maintenance of genome integrity and active homologous recombination in embryonic stem cells. Exp. Mol. Med. 2020, 52, 1220-1229. [CrossRef]

22. Sherr, C.J. Cancer Cell Cycles. Science 1996, 274, 1672-1677. [CrossRef] [PubMed]

23. Ciemerych, M.A.; Sicinski, P. Cell cycle in mouse development. Oncogene 2005, 24, 2877-2898. [CrossRef]

24. ter Huurne, M.; Chappell, J.; Dalton, S.; Stunnenberg, H.G. Distinct Cell-Cycle Control in Two Different States of Mouse Pluripotency. Cell Stem. Cell 2017, 21, 449-455.e4. [CrossRef] [PubMed]

25. Fujii-Yamamoto, H.; Kim, J.M.; Arai, K.-I.; Masai, H. Cell Cycle and Developmental Regulations of Replication Factors in Mouse Embryonic Stem Cells. J. Biol. Chem. 2005, 280, 12976-12987. [CrossRef] [PubMed]

26. Brehm, A.; Miska, E.; McCance, D.J.; Reid, J.L.; Bannister, A.; Kouzarides, T. Retinoblastoma protein recruits histone deacetylase to repress transcription. Nat. Cell Biol. 1998, 391, 597-601. [CrossRef]

27. Stead, E.; White, J.; Faast, R.; Conn, S.; Goldstone, S.; Rathjen, J.; Dhingra, U.; Rathjen, P.; Walker, D.; Dalton, S. Pluripotent cell division cycles are driven by ectopic Cdk2, cyclin A/E and E2F activities. Oncogene 2002, 21, 8320-8333. [CrossRef] [PubMed]

28. Chen, Y.; Lai, N. Pluripotent States of Human Embryonic Stem Cells. Cell. Reprogramming 2015, 17, 1-6. [CrossRef] [PubMed]

29. Pan, G.; Chang, Z.Y.; Schöler, H.; Pei, D. Stem cell pluripotency and transcription factor Oct4. Cell Res. 2002, 12, 321-329. [CrossRef] [PubMed] 
30. Zeineddine, D.; Papadimou, E.; Chebli, K.; Gineste, M.; Liu, J.; Grey, C.; Thurig, S.; Behfar, A.; Wallace, V.A.; Skerjanc, I.S.; et al. Oct-3/4 Dose Dependently Regulates Specification of Embryonic Stem Cells toward a Cardiac Lineage and Early Heart Development. Dev. Cell 2006, 11, 535-546. [CrossRef]

31. Zafarana, G.; Avery, S.R.; Avery, K.; Moore, H.D.; Andrews, P.W. Specific Knockdown of OCT4 in Human Embryonic Stem Cells by Inducible Short Hairpin RNA Interference. Stem. Cells 2009, 27, 776-782. [CrossRef] [PubMed]

32. Card, D.A.G.; Hebbar, P.B.; Li, L.; Trotter, K.W.; Komatsu, Y.; Mishina, Y.; Archer, T.K. Oct4/Sox2-Regulated miR-302 Targets Cyclin D1 in Human Embryonic Stem Cells. Mol. Cell. Biol. 2008, 28, 6426-6438. [CrossRef]

33. Kanai, D.; Ueda, A.; Akagi, T.; Yokota, T.; Koide, H. Oct3/4 directly regulates expression of E2F3a in mouse embryonic stem cells. Biochem. Biophys. Res. Commun. 2015, 459, 374-378. [CrossRef]

34. Julian, L.M.; Vandenbosch, R.; Pakenham, C.A.; Andrusiak, M.G.; Nguyen, A.P.; McClellan, K.A.; Svoboda, D.S.; Lagace, D.C.; Park, D.; Leone, G.; et al. Opposing Regulation of Sox2 by Cell-Cycle Effectors E2f3a and E2f3b in Neural Stem Cells. Cell Stem. Cell 2013, 12, 440-452. [CrossRef]

35. Van Der Laan, S.; Golfetto, E.; Vanacker, J.-M.; Maiorano, D. Cell Cycle-Dependent Expression of Dub3, Nanog and the p160 Family of Nuclear Receptor Coactivators (NCoAs) in Mouse Embryonic Stem Cells. PLoS ONE 2014, 9, e93663. [CrossRef] [PubMed]

36. Faast, R.; White, J.; Cartwright, P.; Crocker, L.; Sarcevic, B.; Dalton, S. Cdk6-cyclin D3 activity in murine ES cells is resistant to inhibition by p16INK4a. Oncogene 2004, 23, 491-502. [CrossRef] [PubMed]

37. Zhang, Y.A.; Xiong, J. p53 Amino-Terminal Nuclear Export Signal Inhibited by DNA Damage-Induced Phosphorylation. Science 2001, 292, 1910-1915. [CrossRef] [PubMed]

38. Sancar, A.; Lindsey-Boltz, L.; Ünsal-Kaçmaz, K.; Linn, S. Molecular Mechanisms of Mammalian DNA Repair and the DNA Damage Checkpoints. Annu. Rev. Biochem. 2004, 73, 39-85. [CrossRef]

39. Eldridge, C.B.; Allen, F.; Crisp, A.; Grandy, R.A.; Vallier, L.; Sale, J.E. A p53-Dependent Checkpoint Induced upon DNA Damage Alters Cell Fate during hiPSC Differentiation. Stem. Cell Rep. 2020, 15, 827-835. [CrossRef] [PubMed]

40. Hyka-Nouspikel, N.; Desmarais, J.; Gokhale, P.J.; Jones, M.; Meuth, M.; Andrews, P.W.; Nouspikel, T. Deficient DNA Damage Response and Cell Cycle Checkpoints Lead to Accumulation of Point Mutations in Human Embryonic Stem Cells. Stem. Cells 2012, 30, 1901-1910. [CrossRef] [PubMed]

41. Orford, K.W.; Scadden, D.T. Deconstructing stem cell self-renewal: Genetic insights into cell-cycle regulation. Nat. Rev. Genet. 2008, 9, 115-128. [CrossRef] [PubMed]

42. Chatterjee, N.; Walker, G.C. Mechanisms of DNA damage, repair, and mutagenesis. Environ. Mol. Mutagen. 2017, 58, 235-263. [CrossRef] [PubMed]

43. Roos, W.; Kaina, B. DNA damage-induced cell death by apoptosis. Trends Mol. Med. 2006, 12, 440-450. [CrossRef] [PubMed]

44. Lam, E.W.-F.; Brosens, J.; Gomes, A.R.; Koo, C.Y. Forkhead box proteins: Tuning forks for transcriptional harmony. Nat. Rev. Cancer 2013, 13, 482-495. [CrossRef] [PubMed]

45. Ye, H.; Kelly, T.F.; Samadani, U.; Lim, L.; Rubio, S.; Overdier, D.G.; A Roebuck, K.; Costa, R.H. Hepatocyte nuclear factor $3 /$ fork head homolog 11 is expressed in proliferating epithelial and mesenchymal cells of embryonic and adult tissues. Mol. Cell. Biol. 1997, 17, 1626-1641. [CrossRef] [PubMed]

46. Gemenetzidis, E.; Bose, A.; Riaz, A.M.; Chaplin, T.; Young, B.D.; Ali, M.; Sugden, D.; Thurlow, J.K.; Cheong, S.-C.; Teo, S.-H.; et al. FOXM1 Upregulation Is an Early Event in Human Squamous Cell Carcinoma and it Is Enhanced by Nicotine during Malignant Transformation. PLoS ONE 2009, 4, e4849. [CrossRef] [PubMed]

47. Bella, L.; Zona, S.; de Moraes, G.N.; Lam, E.W.-F. FOXM1: A key oncofoetal transcription factor in health and disease. Semin. Cancer Biol. 2014, 29, 32-39. [CrossRef] [PubMed]

48. Kwok, C.T.D.; Leung, M.H.; Qin, J.; Qin, Y.; Wang, J.; Lee, Y.L.; Yao, K.-M. The Forkhead box transcription factor FOXM1 is required for the maintenance of cell proliferation and protection against oxidative stress in human embryonic stem cells. Stem. Cell Res. 2016, 16, 651-661. [CrossRef] [PubMed]

49. Tan, Y.; Raychaudhuri, P.; Costa, R.H. Chk2 Mediates Stabilization of the FoxM1 Transcription Factor To Stimulate Expression of DNA Repair Genes. Mol. Cell. Biol. 2007, 27, 1007-1016. [CrossRef]

50. Khongkow, P.; Karunarathna, U.; Gong, C.; Gomes, A.R.; Yagüe, E.; Monteiro, L.J.; Kongsema, M.; Zona, S.; Man, E.P.S.; Tsang, J.W.-H.; et al. FOXM1 targets NBS1 to regulate DNA damage-induced senescence and epirubicin resistance. Oncogene 2014, 33, 4144-4155. [CrossRef] [PubMed]

51. Lee, J.-H.; Paull, T.T. Activation and regulation of ATM kinase activity in response to DNA double-strand breaks. Oncogene 2007, 26, 7741-7748. [CrossRef] [PubMed]

52. Wang, I.-C.; Chen, Y.-J.; Hughes, D.; Petrovic, V.; Major, M.L.; Park, H.J.; Tan, Y.; Ackerson, T.; Costa, R.H. Forkhead Box M1 Regulates the Transcriptional Network of Genes Essential for Mitotic Progression and Genes Encoding the SCF (Skp2-Cks1) Ubiquitin Ligase. Mol. Cell. Biol. 2005, 25, 10875-10894. [CrossRef]

53. Wu, J.; Zhang, X.; Zhang, L.; Wu, C.-Y.; Rezaeian, A.H.; Chan, C.-H.; Li, J.-M.; Wang, J.; Gao, Y.; Han, F.; et al. Skp2 E3 Ligase Integrates ATM Activation and Homologous Recombination Repair by Ubiquitinating NBS1. Mol. Cell 2012, 46, 351-361. [CrossRef]

54. Choudhary, P.; Dodsworth, B.T.; Sidders, B.; Gutteridge, A.; Michaelides, C.; Duckworth, J.K.; Whiting, P.; Benn, C.L. A FOXM1 Dependent Mesenchymal-Epithelial Transition in Retinal Pigment Epithelium Cells. PLoS ONE 2015, 10, e0130379. [CrossRef] [PubMed] 
55. Vassilopoulos, A.; Fritz, K.S.; Petersen, D.R.; Gius, D. The human sirtuin family: Evolutionary divergences and functions. Hum. Genom. 2011, 5, 485-496. [CrossRef] [PubMed]

56. Chen, A.C.H.; Peng, Q.; Fong, S.W.; Yeung, W.S.B.; Lee, Y.L. Sirt1 is regulated by miR-135a and involved in DNA damage repair during mouse cellular reprogramming. Aging 2020, 12, 7431-7447. [CrossRef] [PubMed]

57. Lee, Y.L.; Peng, Q.; Fong, S.W.; Chen, A.C.H.; Lee, K.F.; Ng, E.; Nagy, A.; Yeung, W.S.B. Sirtuin 1 Facilitates Generation of Induced Pluripotent Stem Cells from Mouse Embryonic Fibroblasts through the miR-34a and p53 Pathways. PLoS ONE 2012, 7, e45633. [CrossRef] [PubMed]

58. Chang, H.-C.; Guarente, L. SIRT1 Mediates Central Circadian Control in the SCN by a Mechanism that Decays with Aging. Cell 2013, 153, 1448-1460. [CrossRef] [PubMed]

59. Satoh, A.; Brace, C.S.; Rensing, N.; Cliften, P.; Wozniak, D.F.; Herzog, E.; Yamada, K.A.; Imai, S.-I. Sirt1 Extends Life Span and Delays Aging in Mice through the Regulation of Nk2 Homeobox 1 in the DMH and LH. Cell Metab. 2013, 18, 416-430. [CrossRef] [PubMed]

60. Baur, J.A.; Pearson, K.J.; Price, N.L.; Jamieson, H.A.; Lerin, C.; Kalra, A.; Prabhu, V.V.; Allard, J.S.; Lopez-Lluch, G.; Lewis, K.; et al. Resveratrol improves health and survival of mice on a high-calorie diet. Nature 2006, 444, 337-342. [CrossRef]

61. Vaquero, A.; Scher, M.; Lee, D.; Erdjument-Bromage, H.; Tempst, P.; Reinberg, D. Human SirT1 Interacts with Histone H1 and Promotes Formation of Facultative Heterochromatin. Mol. Cell 2004, 16, 93-105. [CrossRef] [PubMed]

62. Guarente, L.; Picard, F. Calorie Restriction—the SIR2 Connection. Cell 2005, 120, 473-482. [CrossRef]

63. Calvanese, V.; Lara, E.; Suárez-Álvarez, B.; Abu Dawud, R.; Vázquez-Chantada, M.; Martínez-Chantar, M.L.; Embade, N.; López-Nieva, P.; Horrillo, A.; Hmadcha, A.; et al. Sirtuin 1 regulation of developmental genes during differentiation of stem cells. Proc. Natl. Acad. Sci. USA 2010, 107, 13736-13741. [CrossRef]

64. Zhang, Z.-N.; Chung, S.-K.; Xu, Z.; Xu, Y. Oct4 Maintains the Pluripotency of Human Embryonic Stem Cells by Inactivating p53 Through Sirt1-Mediated Deacetylation. Stem. Cells 2014, 32, 157-165. [CrossRef] [PubMed]

65. Jang, J.; Huh, Y.J.; Cho, H.-J.; Lee, B.R.; Park, J.; Hwang, D.-Y.; Kim, D.-W. SIRT1 Enhances the Survival of Human Embryonic Stem Cells by Promoting DNA Repair. Stem. Cell Rep. 2017, 9, 629-641. [CrossRef] [PubMed]

66. Yuan, Z.; Zhang, X.; Sengupta, N.; Lane, W.S.; Seto, E. SIRT1 Regulates the Function of the Nijmegen Breakage Syndrome Protein. Mol. Cell 2007, 27, 149-162. [CrossRef]

67. Li, K.; Casta, A.; Wang, R.; Lozada, E.; Fan, W.; Kane, S.; Ge, Q.; Gu, W.; Orren, D.; Luo, J. Regulation of WRN Protein Cellular Localization and Enzymatic Activities by SIRT1-mediated Deacetylation. J. Biol. Chem. 2008, 283, 7590-7598. [CrossRef] [PubMed]

68. Lee, S.-Y.; Lee, H.; Kim, E.-S.; Park, S.; Lee, J.; Ahn, B. WRN translocation from nucleolus to nucleoplasm is regulated by SIRT1 and required for DNA repair and the development of chemoresistance. Mutat. Res. Mol. Mech. Mutagen. 2015, 774, 40-48. [CrossRef] [PubMed]

69. Rossi, M.L.; Ghosh, A.K.; Bohr, V.A. Roles of Werner syndrome protein in protection of genome integrity. DNA Repair 2010, 9 , 331-344. [CrossRef] [PubMed]

70. Yuan, J.; Chen, J. MRE11-RAD50-NBS1 Complex Dictates DNA Repair Independent of H2AX. J. Biol. Chem. 2010, 285, 1097-1104. [CrossRef] [PubMed]

71. Lee, J.-J.; Lee, H.J.; Son, B.-H.; Kim, S.-B.; Ahn, J.-H.; Ahn, S.D.; Cho, E.Y.; Gong, G. Expression of FOXM1 and related proteins in breast cancer molecular subtypes. Int. J. Exp. Pathol. 2016, 97, 170-177. [CrossRef] [PubMed]

72. Wang, C.; Chen, L.; Hou, X.; Li, Z.; Kabra, N.; Ma, Y.; Nemoto, S.; Finkel, T.; Gu, W.; Cress, W.D.; et al. Interactions between E2F1 and SirT1 regulate apoptotic response to DNA damage. Nat. Cell Biol. 2006, 8, 1025-1031. [CrossRef] [PubMed]

73. Ferrer, C.M.; Lu, T.Y.; Bacigalupa, Z.A.; Katsetos, C.D.; Sinclair, D.; Reginato, M.J. O-GlcNAcylation regulates breast cancer metastasis via SIRT1 modulation of FOXM1 pathway. Oncogene 2017, 36, 559-569. [CrossRef] [PubMed]

74. Lv, C.; Zhao, G.; Sun, X.; Wang, P.; Xie, N.; Luo, J.; Tong, T. Acetylation of FOXM1 is essential for its transactivation and tumor growth stimulation. Oncotarget 2016, 7, 60366-60382. [CrossRef] [PubMed]

75. Zhu, G.-Y.; Shi, B.-Z.; Li, Y. FoxM1 regulates Sirt1 expression in glioma cells. Eur. Rev. Med. Pharmacol. Sci. 2014, 18, 205-211. [PubMed]

76. Qiu, W.; Carson-Walter, E.B.; Liu, H.; Epperly, M.; Greenberger, J.S.; Zambetti, G.P.; Zhang, L.; Yu, J. PUMA Regulates Intestinal Progenitor Cell Radiosensitivity and Gastrointestinal Syndrome. Cell Stem. Cell 2008, 2, 576-583. [CrossRef] [PubMed]

77. Yu, H.; Shen, H.; Yuan, Y.; XuFeng, R.; Hu, X.; Garrison, S.P.; Zhang, L.; Yu, J.; Zambetti, G.P.; Cheng, T. Deletion of Puma protects hematopoietic stem cells and confers long-term survival in response to high-dose $\gamma$-irradiation. Blood 2010, 115, 3472-3480. [CrossRef] [PubMed]

78. Kang, J.W.; Zhan, Z.; Ji, G.; Sang, Y.; Zhou, D.; Li, Y.; Feng, H.; Cheng, T. PUMA facilitates EMI1-promoted cytoplasmic Rad51 ubiquitination and inhibits DNA repair in stem and progenitor cells. Signal Transduct. Target. Ther. 2021, 6, 129. [CrossRef] [PubMed]

79. Baumann, P.; West, S.C. Role of the human RAD51 protein in homologous recombination and double-stranded-break repair. Trends Biochem. Sci. 1998, 23, 247-251. [CrossRef] 